\title{
Nem tudo que reluz é ouro: discutindo prevenção quaternária a partir de ditados populares
}

\author{
All that glisters is not gold: discussing quaternary prevention based on popular sayings \\ No todo lo que reluce es oro: discutiendo prevención cuaternaria a partir de dictados populares
}

Antônio Augusto Dall'Agnol Modesto'ํㅜㅇ

${ }^{1}$ Faculdade de Medicina da Universidade Cidade de São Paulo (UNICID). São Paulo, SP, Brasil.

\section{Resumo}

A Medicina tem convocado as pessoas a realizarem cada vez mais ações preventivas, desde medidas de pressão arterial até a aplicação de novas vacinas; entretanto, médicas e médicos de família e comunidade têm identificado riscos e limitações das ações preventivas, mostrando que nem todas elas são ética ou cientificamente justificáveis. Esse é o escopo da prevenção quaternária, que visa poupar as pessoas de sobremedicalização e procedimentos desnecessários. Vivendo em uma sociedade que prima pela alta tecnologia, onde o terror virou negócio e o autocuidado, uma obsessão, pode ser muito difícil desaconselhar a realização de algum exame ou desprescrever alguma medicação; porém, é exatamente nesse contexto que a prevenção quaternária é profundamente necessária, e a dificuldade de sua prática exige articular outros saberes e recursos além do nível de evidência ou do grau de recomendação de uma ou outra ação. As crenças em saúde são objeto de um cuidado centrado na pessoa, e muitas delas são inspiradas ou traduzidas por ditados populares. Nesse ensaio, discuto o excesso de intervenções e a prevenção quaternária a partir de alguns deles. Analisando frases como "é melhor prevenir do que remediar", apresento os aforismos como ferramentas de compreensão da prevenção quaternária, podendo ser usados por profissionais e docentes para discutir essa prática contra-hegemônica com pacientes e estudantes. Ao articular os saberes popular e profissional, o texto contribui à competência cultural da Atenção Primária à Saúde e ajuda a produzir encontros clínicos mais harmoniosos e a promover um cuidado menos invasivo, medicalizador e danoso.

Palavras-chave: Aforismos e Provérbios como Assunto; Medicina de Família e Comunidade; Prevenção Quaternária; Competência Cultural; Medicalização

Como citar: Modesto AAD. Nem tudo que reluz é ouro: discutindo prevenção quaternária a partir de ditados populares. Rev Bras Med Fam Comunidade. 2019;14(41):1781. http://dx.doi.org/10.5712/rbmfc14(41)1781
Autor correspondente: Antônio Augusto Dall'Agnol Modesto. E-mail: filomedlit@yahoo.com.br Fonte de financiamento: declaram não haver.

Parecer CEP: não se aplica.

Procedência e revisão por pares: revisado por pares. Recebido em: 25/06/2018. Aprovado em: 11/01/2019. 


\begin{abstract}
Medicine has been calling on people to carry out more and more preventive actions, from blood pressure measurements to the application of new vaccines; however, family physicians have been identifying risks and limitations of preventive actions, showing that not all of them are ethically or scientifically justifiable. This is the scope of quaternary prevention, which aims to protect people from over-medicalization and unnecessary procedures. Living in a society that excels in high technology, where terror has turned into business and self-care, an obsession, it can be very difficult to discourage some exam or to unprescribe some medication; but it is precisely in this context that quaternary prevention is deeply necessary, and the difficulty of its practice requires articulating other knowledge and resources beyond the level of evidence or the degree of recommendation of one or another action. Health beliefs are object of person-centered care, and many of them are inspired or translated by popular sayings. In this essay, I discuss the excess of interventions and quaternary prevention from some of them. Analyzing phrases such as "better safe than sorry", I present aphorisms as tools for understanding quaternary prevention, which can be used by professionals and teachers to discuss this counter-hegemonic practice with patients and students. By articulating popular and professional knowledge, the text contributes to the cultural competence of Primary Health Care and helps to produce more harmonious clinical encounters and to promote less invasive, medicalizing and harmful care.
\end{abstract}

Keywords: Aphorisms and Proverbs as Topic; Family Practice; Quaternary Prevention; Cultural Competency; Medicalization

\title{
Resumen
}

La Medicina ha convocado a las personas a realizar cada vez más acciones preventivas, desde medidas de presión arterial hasta la aplicación de nuevas vacunas; sin embargo, médicas y médicos de familia y comunidad han identificado riesgos y limitaciones de las acciones preventivas, mostrando que no todas ellas son ética o científicamente justificables. Este es el alcance de la prevención cuaternaria, que intenta ahorrar a las personas de sobremedicalización y procedimientos innecesarios. En una sociedad que prima por la alta tecnología, donde el terror se volvió negocio y el autocuidado, una obsesión, puede ser muy difícil desaconsejarse la realización de algún examen o desprescribir alguna medicación, pero es precisamente en ese contexto que la prevención cuaternaria es profundamente necesaria, y la dificultad de su práctica exige articular otros saberes y recursos más allá del nivel de evidencia o del grado de recomendación de cada acción. Muchas creencias en salud son inspiradas o traducidas por dichos populares; en este ensayo, discuto el exceso de intervenciones y la prevención cuaternaria a partir de algunos de ellos. Analizando frases como "más vale prevenir que curar", presento los aforismos como herramientas de comprensión de la prevención cuaternaria, pudiendo ser usados por profesionales y docentes para discutir esa práctica contra-hegemónica con pacientes y estudiantes. Al articular los saberes popular y profesional, el texto contribuye a la competencia cultural de la Atención Primaria a la Salud y ayuda a producir encuentros clínicos más armoniosos y a promover un cuidado menos invasivo, medicalizador y dañino.

Palabras clave: Aforismos y Proverbios como Asunto; Medicina Familiary Comunitaria; Prevención Cuaternaria; Competencia Cultural; Medicalización

\section{Introdução}

A Medicina tem convocado as pessoas a realizarem cada vez mais ações preventivas, desde uma simples medida de pressão arterial até exames mais incômodos como o Papanicolaou e o toque retal, passando por ultrassonografias, dosagens séricas e aplicação de novas vacinas. Algumas dessas ações estão associadas a "meses coloridos", como o Outubro Rosa do câncer de mama, o Novembro Azul do câncer de próstata e o Julho Amarelo das hepatites virais.

Entretanto, médicas e médicos de família e comunidade têm identificado riscos e limitações das ações preventivas, mostrando que nem todas elas são ética ou cientificamente justificáveis. Esse é o escopo da prevenção quaternária (P4), prática que visa poupar as pessoas de sobremedicalização e procedimentos desnecessários. ${ }^{1-4}$ Dois de seus principais recursos são a Medicina Baseada em Evidências, que busca combinar as melhores informações científicas disponíveis com a experiência do clínico e os valores da pessoa atendida, ${ }^{5,6}$ e o Método Clínico Centrado na Pessoa, que valoriza a escuta e a elaboração de planos compartilhados de cuidado. As ideias sobre saúde também são objeto de uma prática médica centrada na pessoa, ${ }^{7,8}$ que pode evitar cascatas diagnósticas e terapêuticas desnecessárias, ${ }^{9,10}$ e muitas dessas ideias são inspiradas ou traduzidas por ditados populares. 
Nesse ensaio, discuto o excesso de intervenções e a prevenção quaternária a partir de alguns ditados populares. Analisando frases como "é melhor prevenir do que remediar" e "não se mexe em time que está ganhando", apresento os aforismos como ferramentas de compreensão da P4, podendo ser usados por profissionais e docentes para discutir essa prática contra-hegemônica com pacientes e estudantes. Além disso, ao articular os saberes popular e profissional, ${ }^{11,12}$ o texto contribui à competência cultural da Atenção Primária à Saúde e ajuda a promover encontros clínicos mais harmoniosos e promotores de um cuidado menos invasivo, medicalizador e danoso.

\section{Medicalização e prevenção quaternária}

Clark e Leavell ${ }^{13}$ descreveram o processo saúde-doença de forma linear, em que um corpo previamente sadio é acometido por uma doença com um período assintomático inicial e um período sintomático progressivo. Tomando a sífilis como modelo, os autores delimitaram períodos de pré-patogênese (sem doença) e patogênese (com doença), tendo essa segunda uma ou mais fases com e sem sintomas. Para cada uma das etapas desse processo, correspondem diferentes níveis de prevenção: a primária visa impedir o surgimento de doenças; a secundária inclui o diagnóstico precoce (assintomático ou sintomático), o tratamento adequado e as ações para evitar sequelas e limitar a invalidez; e a terciária objetiva a reabilitação diante de processos patológicos instalados. ${ }^{14}$

Por sua vez, Marc Jamoulle descreveu o processo saúde-doença como uma articulação entre a visão dicotômica do médico sobre a presença ou ausência de doença (em inglês, disease) e a visão gradativa do paciente sobre sentir-se ou não doente (illness, a experiência da doença). ${ }^{1,2,15,16}$ A relação entre essas visões coloca quatro situações, correspondentes a quatro níveis de prevenção. No primeiro grupo estão pessoas que se sentem saudáveis e de fato não têm doença, sendo alvo da prevenção primária, cujo exemplo são as vacinas. No segundo grupo estão pessoas que têm alguma doença (pela perspectiva médica), mas não têm sintomas, ou têm sintomas iniciais ou indiferenciados; elas são alvo da prevenção secundária. Alguns exemplos são as sorologias para doenças sexualmente transmissíveis e as buscas ativas em geral. Quando médico e paciente concordam sobre a presença de doença (terceiro grupo), cabe a prevenção terciária, que envolve tratamento, prevenção de sequelas e reabilitação - é o caso de uma pessoa com gonartrose ou epilepsia.

No quarto grupo estão pessoas não contempladas no modelo de Leavell e Clark: aquelas que não têm doença de um ponto de vista médico ético e científico (no disease), mas sentem-se doentes (feel ill) ou se consideram alvo de intervenções médicas preventivas ou curativas. Elas são destinatárias das ações de prevenção quaternária, que buscam prevenir os excessos da Medicina. ${ }^{1,2,15-17}$

De acordo com a World Organization of National Colleges, Academies, and Academic Associations of General Practitioners/Family Physicians (WONCA), prevenção quaternária é a "ação realizada para identificar um paciente em risco de supermedicalização, para protegê-lo de novas invasões médicas, e para sugerir a ele intervenções eticamente aceitáveis". ${ }^{14}$ Jamoulle e Gusso são mais abrangentes ao definirem a P4 como a "ação feita para identificar uma pessoa ou população em risco de supermedicalização, para protegê-los de uma intervenção médica invasiva e sugerir procedimentos científica e eticamente aceitáveis". ${ }^{2}$ 
Já Martins et al., acreditando que a P4 deveria estar na mente dos médicos cada vez que considerassem uma intervenção, propõem uma terceira definição: "ação tomada para proteger indivíduos (pessoas/ pacientes) de intervenções médicas que provavelmente causarão mais dano que benefício". ${ }^{17}$ Como se vê, todas elas se apoiam sobre o princípio hipocrático primum non nocere: antes de tudo, não prejudicar.

Talvez os exemplos mais fáceis para o quarto grupo sejam pessoas hipocondríacas, com transtornos somatoformes ou sintomas medicamente inexplicáveis. Muitas delas peregrinam por médicos e profissionais de saúde em geral, fazendo exames e tentando tratamentos frustrantes e muitas vezes danosos, quando teriam mais sucesso com uma abordagem integral e centrada na pessoa. ${ }^{18}$ No entanto, o fenômeno da medicalização, a valorização excessiva dos exames complementares e a popularização dos check-ups têm criado um grupo maior ainda de pessoas merecedoras de prevenção quaternária.

Cada vez mais temos trazido questões de outras esferas da vida (familiar, política, afetiva etc.) para o âmbito da Medicina hegemônica. Isso significa entender essas questões pelo paradigma biomédico e esperar que a Medicina (e o conjunto de saberes e práticas sócio-históricas que serve de referências para profissionais de saúde em geral) dê respostas eficazes a nossos problemas. ${ }^{19}$

Aalimentação, por exemplo, tem sofrido esse processo: a comida tem deixado os campos da cultura e do prazer em favor de uma "saúde" focada na suplementação de nutrientes. Nos mercados, adjetivos como "suculento" ou "fresquinho" vêm dando lugar a frases como "fonte de vitamina E" e "fortalece os ossos"; nos restaurantes, os cardápios oferecem combinações de "salada e proteína", reduzindo a experiência promovida por um bife na chapa ou cogumelos refogados ao cumprimento de necessidades nutricionais diárias.

Paralelamente, nosso medo ancestral da morte tem sido capitalizado por meio de exames desnecessários e práticas sem evidência científica e não promotoras de autonomia. ${ }^{20,21}$ Uma pessoa que atendesse a todas as campanhas de meses coloridos, seguisse todas as recomendações de sociedades de especialistas e atentasse às indicações de programas de TV como o Bem Estar, da Rede Globo, ${ }^{22}$ acabaria dedicando boa parte dos seus dias (e de sua renda) a consultas médicas, realização de exames e uso de medicamentos e suplementos, cada um deles com seus riscos e efeitos colaterais - fora as horas de preocupação e vigilância do próprio corpo.

\section{"A voz do povo é a voz de Deus": um pouco sobre ditados populares}

Apesar do vox populi, vox Dei parecer se referir ao senso comum, à opinião pública sobre um assunto ou à importância da maioria, Câmara Cascudo acredita que a expressão tenha origem nas consultas divinas no templo de Hermes em Acaia, na Grécia antiga. Lá, o consulente sussurrava seu desejo ao ouvido do ídolo, formulando sua súplica angustiada; depois

erguia-se, tapando as orelhas com as mãos, e vinha até o átrio do templo, onde arredava os dedos, esperando ouvir as primeiras palavras dos transeuntes. Essas palavras eram a resposta do oráculo, a decisão do deus. Vox populi, vox Dei, na sua expressiva legitimidade. ${ }^{23}$ 
Semelhantemente, em Portugal e no Nordeste brasileiro, há o costume de rezar elaborando uma pergunta e, em seguida, colocar-se em um lugar público (como uma praça ou atrás de uma porta de igreja), aguardando que a resposta surja através de uma frase ou palavra apanhada das vozes dispersas dos que passam. A voz do povo transmite a resposta de Deus às preces, comumente destinadas a Santa Rita dos Impossíveis e, no Brasil, também ao profeta Zacarias e ao apóstolo São Pedro.

Speake e Simpson definem um provérbio como "uma fala tradicional que oferece conselho ou apresenta uma moral de forma curta e marcante". ${ }^{24}$ Os editores do Dicionário Oxford de Provérbios os dividem em três categorias: 1) afirmações abstratas que expressam verdades gerais, como "quem está na chuva é para se molhar"; 2) observações específicas do dia-a-dia que apontam algo geral, como "não ponha todos os ovos em uma cesta só"; e 3) ditos de áreas particulares do saber popular e folclore, como o rural "não tire as botinas antes de chegar à beira do córrego".

Muitos provérbios podem ser usados para traduzir crenças quanto à saúde, o adoecimento, o cuidado e a prevenção. Eat an apple on going to bed, and you'll keep the doctor from earning his bread ("coma uma maçã ao ir para a cama e você vai deixar o médico sem grana"), por exemplo, é um ditado galês, mais conhecido na versão an apple a day keeps the doctor away ("uma maçã por dia deixa o médico longe") ${ }^{24} \mathrm{e}$ como a rima "uma maçã por dia traz saúde e alegria". Em 2017, o Centro de Pesquisa em Processos Redox em Biomedicina (Redoxoma), sediado na Universidade de São Paulo, aproveitou quatro ditados populares em uma campanha de informação sobre radicais livres e saúde: "diz-me o que comes e te direi quem és"; "velho que se cuida, cem anos dura"; "devagar se vai longe"; e "é melhor prevenir do que remediar". ${ }^{25}$ Todos eles indicam que há medidas a tomar hoje que implicarão em uma vida melhor e mais longa.

Começaremos discutindo um dos mais célebres deles.

\section{“É melhor prevenir do que remediar” (prevention is better than cure)}

Melius tamem est (ut videtur) in tempore occurrere, quam post causam vulneratam remedium querere

“É melhor (como parece) enfrentar a tempo que buscar remédio após o dano", diz a frase de Henry de Bracton (c.1210-c.1268), clérigo e jurista inglês, em De Legibus \& consuetudinibus Angliae, escrito por volta de 1240 e publicado em 1569. Sem dúvida, prevenir infecções pela lavagem das mãos antes de manusear alimentos ou prevenir doenças sexualmente transmissíveis pelo uso do preservativo é muito melhor que os respectivos remédios, enquanto a morte de mães e crianças pela falta de uma boa atenção pré-natal são danos irremediáveis.

No entanto, nem sempre prevenir é melhor do que remediar. Essa observação contraintuitiva se relaciona, em parte, à diferença entre plausibilidade biológica e efetividade clínica. Não basta que uma intervenção faça sentido do ponto de vista fisiológico: é necessário comprovar sua eficiência por meio de ensaios clínicos com o mínimo de vieses possível, e que estudem desfechos relevantes como qualidade de vida e mortalidade. ${ }^{6}$ 
Um exemplo importante é o uso de estatinas para prevenção primária de infartos do miocárdio fatais. Acredita-se que o colesterol LDL aumentado seja um fator de risco para infarto do miocárdio, e as estatinas são fármacos que diminuem o LDL sanguíneo; logo, espera-se que o uso de estatinas por pessoas com LDL alto diminua sua mortalidade por infarto. A plausibilidade biológica (mais remédio, menos colesterol; menos colesterol, menos risco de infarto) é facilmente traduzida pela diminuição do risco calculado de evento cardiovascular em dez anos, de cujo cálculo o LDL (agora menor, às custas da estatina) faz parte.

Porém, revisões sistemáticas de ensaios clínicos demonstram que o uso de estatinas por pessoas de 40 a 75 anos sem evento cardiovascular prévio, com um ou mais fatores de risco (dislipidemia, diabete, hipertensão ou tabagismo), mas um risco calculado de evento cardiovascular em dez anos menor que $10 \%$ (ou seja, baixo), não diminui sua mortalidade geral ou por eventos cardiovasculares, e tem pequeno impacto na chance de infartos ou derrames não fatais. ${ }^{26,27}$ Isso deve ser lembrado ao considerar o uso de uma droga que tem como efeitos colaterais dor muscular, hepatite medicamentosa e diabete, e que pode interagir negativamente com outras medicações.

Outro exemplo é o rastreamento de hipotireoidismo. Apesar de se tratar de uma doença benigna e, em geral, facilmente tratável (ou seja, que não deveríamos ter pressa para diagnosticar), muitos médicos têm solicitado dosagens de TSH séricos em pessoas assintomáticas. Isso produz muitos dos confusos diagnósticos de "hipotireoidismo subclínico" 28 - subclínico como deveria permanecer, já que tratá-lo aparentemente não modifica a mortalidade geral ou por eventos cardiovasculares. ${ }^{29,30} \mathrm{Em}$ outras palavras, o exame diagnostica uma doença que não é doença e acaba levando pessoas saudáveis a usar doses baixas de levotiroxina pelo resto de suas vidas, sem que isso as faça viver mais ou melhor.

É bom frisar a diferença entre exames solicitados para pessoas assintomáticas (como em rastreios ou check-ups) daqueles pedidos para quem apresenta sintomas, que fazem parte da investigação diagnóstica. A dosagem de TSH, por exemplo, estaria muito bem indicada a uma pessoa que viesse ganhando peso, tendo muito sono e observando alterações na pele ou cabelos.

\section{"Seguro morreu de velho"}

Semelhante ao aforismo anterior, este é comum entre pessoas que buscam (ou indicam) rastreamentos ou check-ups regulares visando uma garantia de que a saúde está perfeita e de que não há nenhum problema oculto que possa vir a afetá-la - como se a sensação de bem-estar não fosse suficiente.

Todas as ações preventivas, no entanto, estão fundamentadas no conceito de risco. Para Almeida Filho e Rouquayrol,

risco é o correspondente epidemiológico do conceito matemático de probabilidade. Neste caso, a probabilidade se refere a modelos abstratos de distribuição populacional, não redutível às chances de um indivíduo particular frente a um diagnóstico ou prognóstico. (...) podemos definir Risco como a probabilidade de ocorrência de uma doença, agravo, óbito ou condição relacionada à saúde (incluindo cura, recuperação ou melhora), em uma população ou grupo, durante um período de tempo determinado. (...) Não se pode aplicar esse modelo

para estabelecer o diagnóstico ou prognóstico de um indivíduo em particular, porque o conceito de risco refere-se exclusivamente ao grupo como um todo. [grifos do autor]. ${ }^{31}$ 
As pessoas nos lembram disso frequentemente durante o aconselhamento para pararem de fumar, ao citarem um parente que fumou a vida toda e morreu muito idoso. Elas nada mais fazem do que lembrar-nos que risco não é certeza, e que os dados populacionais não podem ser aplicados aos indivíduos sem as traduções necessárias. Ademais, o corpo é algo tão dinâmico que um eletrocardiograma normal hoje diz muito pouco sobre a chance de uma pessoa morrer de infarto anos depois, enquanto um hemograma normal hoje não diz nada sobre uma anemia que se resolveu sozinha três meses antes.

Voltando à diferenciação de plausibilidade biológica e efetividade clínica, tomemos o rastreamento do câncer de próstata como exemplo. O antígeno prostático específico (PSA) sobe nos quadros de neoplasia prostática; assim, parece coerente que se dose regularmente esse antígeno, pois uma elevação inesperada pode significar um câncer de próstata inicial, e é de se esperar que um câncer tratado "mais cedo", "quando ainda é pequeno", seja mais facilmente erradicado. Entretanto, o seguimento de grandes populações de homens que dosaram e que não dosaram PSA regularmente por mais de dez anos não demonstrou diminuição da mortalidade geral entre os que fazem o rastreio. Quando muito, há uma pequena diminuição da mortalidade por câncer de próstata - não compensada pelo risco de falsos positivos e biópsias e tratamentos desnecessários, que podem levar à disfunção erétil e incontinência urinária. ${ }^{32,33}$

Nesse caso, seguro não morre mais velho, mas pode morrer impotente ou usando fraldas.

\section{“É melhor pecar pelo excesso do que pela falta” (better [be] safe than sorry)}

However, as the tinker went through that process again, and still repeated "one, two, three", Rory said, impatiently: "Tare an' ouns! Is it thim owld kittles you're reckonin' agm?"

"Jist countin' thim - is there any harm in that?" said the tinker; "it's better be sure than sorry"

"No entanto, como o funileiro passou por esse processo novamente, e ainda repetia 'um, dois, três', Rory disse, impaciente: 'Lágrimas e feridas de Cristo! São aqueles pinos velhos que você está contando de novo?'

'Apenas contando eles - há algum mal nisso?' disse o funileiro; 'é melhor ter certeza que lamentar"”

O diálogo do livro Rory O’More: A National Romance, de 1837, escrito por Samuel Lover (1797-1868), artista inglês, mostra ao mesmo tempo como a prevenção é valorizada e como pode ser inconveniente.

Pedir exames por desencargo de consciência ou prescrever medicações porque não custa nada parecem sempre a coisa certa a fazer: é mais fácil perdoar efeitos colaterais de intervenções do que aceitar eventuais intercorrências em uma observação expectante. Em termos bioéticos, seria melhor errar por imprudência que por negligência; ao mesmo tempo, a ideia de pecado sacraliza o excesso de cuidado, como se eventuais exageros terapêuticos ou investigativos gozassem do perdão divino decorrente de seu bom propósito.

Porém, como diria São Bernardo de Clairvaux por volta de 1150, l'enfer est plein de bonnes volontés ou désirs, "o inferno está cheio de boas intenções ou desejos"24,34 - e, em Medicina, o excesso é pecado mortal. Pesquisadores estimam que o erro médico seja a terceira causa de morte nos Estados Unidos, incluindo eventos como complicações de investigações excessivas ou cirurgias desnecessárias ${ }^{35,36}$ frequentemente resultantes de rastreamentos inadequados. 
É difícil investigar os impactos do excesso de intervenções. Sabemos que artigos com resultados positivos, que favorecem o uso de medicamentos e procedimentos, têm mais chance de serem publicados do que artigos com resultados negativos, nulos ou que demonstram efeitos colaterais. Essa tendência de "os resultados publicados estarem sistematicamente diferentes da realidade" ${ }^{37}$ se chama viés de publicação, e pode influenciar a seleção de pesquisas para compor meta-análises. Uma revisão envolvendo 1106 meta-análises da Cochrane Database of Systematic Reviews que comparavam tratamento com placebo ou ausência de tratamento mostrou que, nas meta-análises de eficácia, desfechos favorecendo o tratamento tinham $27 \%$ a mais de probabilidade de serem incluídos que outros desfechos, e, nas meta-análises de segurança, resultados mostrando ausência de efeitos adversos tinham $78 \%$ a mais de probabilidade de serem incluídos que resultados demonstrando que havia efeitos adversos. ${ }^{38}$ Outra revisão, desta vez envolvendo 635 ensaios financiados pelo National Institute of Health dos Estados Unidos com início e conclusão registrados na plataforma ClinicalTrials.gov entre 2005 e 2008, demonstrou que menos da metade desses ensaios foram publicados após 30 meses de sua conclusão. ${ }^{39}$

Segundo Pereira et al., a não publicação de resultados pode se dever ao desinteresse dos editores de periódicos científicos em divulgar resultados negativos e/ou sem significância estatística ou à decisão de autores e financiadores da pesquisa de não submeter achados desfavoráveis para publicação. ${ }^{37}$ Como se diz em italiano, la vittoria trova cento padri, e nessuno vuole riconoscere l'insuccesso - "a vitória tem cem pais, e ninguém quer reconhecer o fracasso".

A presença desse viés nas revisões sistemáticas pode ser identificada por meio de gráfico de funil e de testes estatísticos, recomendada para meta-análises com dez estudos ou mais. Eles se baseiam em questões de estimativa e precisão - por exemplo, avaliando como estudos pouco precisos influenciam os resultados da revisão e visitando bases de registros de estudos (como o ClinicalTrials.gov ou a Plataforma Brasi ${ }^{40}$ ) à procura de pesquisas que não vieram a ser publicadas. ${ }^{37}$

\section{"Nem tudo que reluz é ouro"}

Let's hurry, hurry, use the new drug before it stops curing

"Vamos nos apressar, apressar usar a nova droga, antes que pare de curar"

Armand Trousseau (1801 - 1867), médico francês.

Novas descobertas em Medicina sempre animam o público em geral: parece que, quando se descobrem novos exames ou novos tratamentos, todos nós ficamos um pouco mais distantes da morte. No entanto, a informação sobre saúde divulgada pelos meios de comunicação não é neutra, como não é neutra a ciência que a produz, nem são neutras as relações que fazem com que algumas informações 
ganhem mais relevância que outras, ${ }^{20,21,41}$ gerando um viés de mídia que se soma ao viés de divulgação que mostramos anteriormente. Assim, apesar de sua função potencialmente benéfica, ${ }^{42}$ a mídia frequentemente gera demandas em saúde de forma danosa. ${ }^{20,21,43-45}$

Moynihan et al. (2002) mostram como a indústria farmacêutica, aliada a médicos e grupos de pacientes, utiliza-se da mídia para criar doenças e doentes, numa forma de medicalização chamada de disease mongering ou "promoção da doença". As estratégias envolvidas nesse processo e alguns exemplos são: 1) classificar transtornos comuns da vida como problemas médicos, como a calvície; 2) fazer sintomas leves parecerem indícios de doenças graves, como na síndrome do cólon irritável; 3) apresentar problemas pessoais ou sociais como problemas médicos, como entender a timidez como fobia social; 4) transformar fatores de risco em enfermidades, como se faz com a osteoporose; e 5) adaptar indicadores de prevalência para aumentar o tamanho de um problema médico, maximizando o público-alvo de intervenções, como ocorre com a disfunção erétil. ${ }^{20}$

Non omne quod nitet aurum est - ou, como popularizado por Shakespeare na peça "O mercador de Veneza" (1596), all that glisters is not gold. ${ }^{24}$ Nem tudo que reluz é ouro, nem todas as descobertas são avanços: é preciso ter prudência quanto às novas intervenções, considerando a influência do complexo médico-hospitalar sobre a pesquisa e a prática médicas. Para dar apenas um exemplo, um estudo recente envolvendo 131 das 154 sociedades de especialidades médicas na Itália demonstrou que 64,9\% receberam financiamento da indústria para sua última conferência e 29\% tinham alguma logomarca da indústria em seu sítio de internet. Apenas $45,6 \%$ das sociedades tinha um estatuto que mencionava a questão do conflito de interesse. ${ }^{46}$

Felizmente, há diversos recursos online que reúnem informação livre de conflitos de interesse para a tomada de decisões mais acertadas. Alguns são o portal Cochrane, cuja missão é resumida no slogan "evidência confiável, decisões informadas, melhor saúde"; ${ }^{47}$ o sítio da United States Preventive Services Task Force; ${ }^{48}$ o sítio The $N N T{ }^{49}$ que reúne dados sobre o número necessário para tratar e o número necessário para causar dano de diversas intervenções; e o portal Saúde Baseada em Evidências, iniciativa do Ministério da Saúde em parceria com a Organização Pan-Americana de Saúde (OPAS/OMS), desenvolvida pela Universidade Federal do Rio Grande do Norte. ${ }^{50}$

\section{"Não se mexe em time que está ganhando"}

Em maio de 1977, Bert Lance, diretor do Office of Management and Budget dos Estados Unidos, declarou que o país poderia economizar bilhões se o governo assumisse um único mote: if ain't broke, don't fix it - se não está quebrado, não conserte. ${ }^{24} \mathrm{O}$ equivalente britânico é let well alone, algo como "deixe estar o que está bem", e, no Brasil, usamos o futebolístico "não se mexe em time que está ganhando" para indicar que mudanças podem trazer prejuízos, mesmo sendo tentativas de melhora. /l meglio è nemico del bene - o melhor é inimigo do bom, provérbio popularizado por Voltaire ${ }^{24}$ mas de origem italiana, como registra Orlando Pescetti em Proverbi italiani, de 1603.

No que tange à saúde, o dentista Daniel Laskin comentava pouco antes de Marc Jamoulle que, para alguns pacientes da cirurgia odontológica, era melhor não fazer nada, e que os profissionais deveriam 
resistir à tentação de operar uma pessoa porque não havia mais o que fazer por ela. "Saber o que fazer e quando fazer é uma habilidade que já temos, saber o que não fazer e quando não fazer é uma arte que todos temos que aprender". ${ }^{51}$

\section{“Não jogar fora o bebê junto com a água do banho"}

É difícil crer que, na Idade Média, as pessoas tomavam banho de banheira em uma água tão suja que seria possível perder um bebê nela e jogá-lo fora - até porque, sem encanamento e no frio europeu, um banho de banheira exigia um esforço enorme e estava disponível para poucos. A frase Das Kind mit dem Bade ausschütten apareceu impressa pela primeira vez em 1512 no livro satírico Narrenbeschwörung ("Evocação aos tolos"), de Thomas Murner, e a gravura que a acompanha (Figura 1) mostra que uma mãe poderia encher um balde para banhar uma criança, mas dificilmente seria capaz de jogá-la fora por engano.

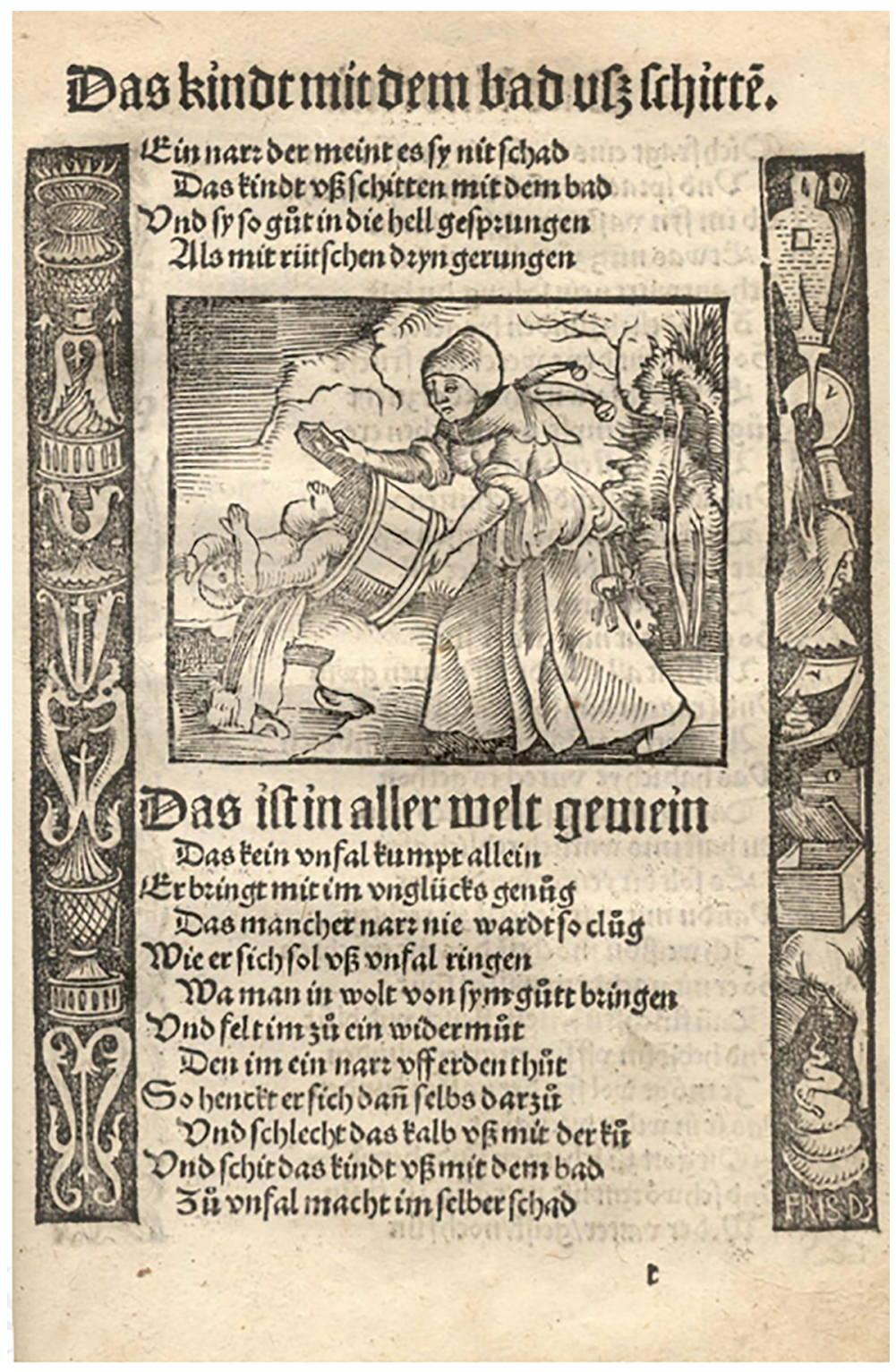

Figura 1. Página da "Evocação aos tolos", de Thomas Murner (1512). Fonte: Wikimedia Commons. 
De qualquer forma, "não jogar o bebê fora junto com a água do banho" significa ter prudência ao eliminar ou corrigir algo. Um exemplo é a vacinação: embora a vacina de influenza ainda mereça questionamentos, ${ }^{52}$ não se pode negar a enorme importância de quase todas as demais. A vacinação contra varíola foi a principal responsável por erradicar, nos anos 80 , uma doença de mais de mil anos, ${ }^{53}$ enquanto moléstias potencialmente fatais como o tétano e a febre amarela podem ser prevenidas pela imunização.

\section{“Mais vale um pássaro na mão do que dois voando"}

A consulta é um encontro entre especialistas: os médicos, especialistas em Medicina e doenças, e os pacientes, especialistas em seus corpos e sensações. Algumas pessoas convivem com anos de adoecimento antes que nós as conheçamos e ofereçamos nossas soluções mirabolantes; outras tiveram experiências tão terríveis com a Medicina que é difícil convencê-las de qualquer conduta; outras ainda cristalizaram crenças e comportamentos em saúde durante a elaboração de perdas e ganhos. ${ }^{8}$

Como se dizia na França no início do século XV, mieux vaut aucun bien que néant, "mais vale qualquer bem que nada". Nessas situações, convém se pautar pela redução de danos: desprescrever qualquer droga inadequada ou contraindicar qualquer exame desnecessário, seja para rastreio ou para um suposto diagnóstico, já é um avanço. Às vezes, a vitamina $D$ fica, mas a estatina sai; noutras, mantém-se a dosagem semestral de colesterol, mas abandonam-se a de enzimas hepáticas e hormônios tireoidianos. E quantas mulheres não ficarão felizes em saber que poderão realizar a colpocitologia oncótica a cada três anos, depois de dois exames normais separados por um ano, ${ }^{54}$ e que não precisam realizar ultrassonografias transvaginais de rotina! ${ }^{55}$

A prática da prevenção quaternária deve ser embasada em um saber técnico atualizado e abrangente, que suporte a prática frequentemente trabalhosa de uma ética da negativa, em que "não se faz o que não é necessário fazer" em favor de menos iatrogenia e mais saúde. ${ }^{45}$ Ao contrário do que muitos profissionais pensam, uma revisão sistemática mostrou que "testes diagnósticos para sintomas com baixo risco de doença grave contribuem muito pouco em assegurar pacientes, diminuir sua ansiedade ou resolver seus sintomas, apesar de os testes poderem reduzir consultas adicionais à atenção primária". ${ }^{56}$

Conhecer as crenças e medos da pessoa atendida ajuda na ressignificação do processo saúdeadoecimento, em que o profissional caminha entre o atendimento às demandas medicalizadas e potencialmente danosas do usuário e uma conduta tão negativa que leve o usuário a romper a relação com o profissional ou o serviço, tamanha sua frustração. ${ }^{45}$

\section{Considerações finais}

Que Deus fala através do povo? Estaremos orando para Hígia, deusa da saúde, e ouvindo a resposta de Hermes, deus do comércio?

O símbolo de Asclépio, deus da Medicina - um bastão de madeira enroscado por uma serpente - é frequentemente confundido com o símbolo de Hermes - um bastão de ouro ou ferro com duas serpentes enroscadas ao seu redor e um par de asas na extremidade superior, alado como os pés do deus do comércio, das comunicações e das viagens. Infelizmente, a confusão entre Medicina e comércio vem acontecendo na prática. 
Vivendo em uma sociedade que prima pela alta tecnologia, onde o terror virou negócio e o autocuidado, uma obsessão, ${ }^{21}$ pode ser muito difícil desaconselhar a realização de algum exame ou desprescrever alguma medicação. Porém, é exatamente nesse contexto que a prevenção quaternária é profundamente necessária, ${ }^{4,17,45,57}$ e a dificuldade de sua prática exige articular outros saberes e recursos além do nível de evidência ou do grau de recomendação de uma ou outra ação.

Uma das principais atribuições do médico é "traduzir o discurso, os sinais os sintomas do paciente para chegar ao diagnóstico da doença, ou seja, decodificar illness em disease". ${ }^{11}$ Vínculo, longitudinalidade, empatia e habilidades de comunicação são condições e ferramentas necessárias para uma prática médica mais compreensiva e menos invasiva.

Se os ditados populares traduzem crenças em saúde, eles podem ser usados para entender e problematizar expectativas quanto ao cuidado e ajudar a evidenciar os limites da Medicina. Encontrando seus limites, a Medicina se humaniza; no flerte com o popular, ela vira Arte.

\section{Contribuição dos autores}

Declaro que fui responsável por toda a produção do artigo e a pesquisa relacionada.

\section{Conflito de interesses}

Declaro não haver.

\section{Referências}

1. Kuehlein T, Sghedoni D, Visentin G, Gérvas J, Jamoulle M. Prevenção quaternária, uma tarefa do clínico geral. Primary Care. 2010;10(18):350-4.

2. Jamoulle M, Gusso G. Prevenção quaternária: primeiro não causar dano. In: Gusso G, Lopes JMC, org. Tratado de Medicina de Família e Comunidade: princípios, formação e prática. Porto Alegre: Artmed; 2012. p. 205-11.

3. Cardoso RV. Quaternary prevention: a gaze on medicalization in the practice of family doctors. Rev Bras Med Fam Comunidade. 2015;10(35):1-10. http://dx.doi.org/10.5712/rbmfc10(35)1117

4. Jamoulle M. Quaternary prevention, an answer of family doctors to overmedicalization. Int J Health Policy Manag. 2015;4(2):61-4. http:// dx.doi.org/10.15171/ijhpm.2015.24

5. Nordenstrom J. Medicina baseada em evidências: seguindo os passos de Sherlock Holmes. Porto Alegre: Artmed; 2008.

6. Stein AT. Medicina Baseada em Evidências aplicada à prática do médico de família. In: Gusso G, Lopes JMC, eds. Tratado de Medicina de Família. Porto Alegre: Artmed; 2012.

7. McWhinney IR, Freeman T. Manual de Medicina de Família e Comunidade. Porto Alegre: Artmed; 2001. p. 151-204.

8. Pendleton D, Schofield T, Tate P, Havelock P. A Nova Consulta - desenvolvendo a comunicação entre médico e paciente. Porto Alegre: Artmed; 2011.

9. Stewart M, Brown JB, Donner A, McWhinney IR, Oates J, Weston WW, et al. The impact of patient-centered care on outcomes. J Fam Pract. 2000;49(9):796-804.

10.Pérez-Fernández M, Gérvas J. El efecto cascada: implicaciones clínicas, epidemiológicas y éticas. Med Clin (Barc). 2002;118(2):65-7. http://dx.doi.org/10.1016/S0025-7753(02)72283-5

11. Oliveira FA. Antropologia nos serviços de saúde: integralidade, cultura e comunicação. Interface (Botucatu). 2002;6(10):63-74. http:// dx.doi.org/10.1590/S1414-32832002000100006

12. Silva-Junior ND, Gonçalves G, Demétrio F. Escolha do itinerário terapêutico diante dos problemas de saúde: considerações socioantropológicas. Rev Eletrônica Disc Hist. 2013;1(1):1-12. 
13. Clark EG, Leavell H. Níveis de aplicação da Medicina Preventiva. In: Leavell H, Clark EG, orgs. Medicina Preventiva. Rio de Janeiro: FENAME; 1977. p. 11-36.

14. Bentzen N, ed. Wonca Dictionary of General/Family Practice. Copenhagen: Maanedsskrift for Praktisk Laegegerning; 2003.

15. Jamoulle M. Information et Informatisation en Médecine Générale. In: Les Informa-g-iciens. Namur: Presses Universitaires de Namur. 1986. p. 193-209.

16. Jamoulle M, Roland M. Quaternary prevention [Internet]. 1995. [cited 2018 Jun 23]:1-6. Available from: http://www.ph3c.org/PH3C/ docs/27/000103/0000261.pdf

17. Martins C, Godycki-Cwirko M, Heleno B, Brodersen J. Quaternary prevention: reviewing the concept. Eur J Gen Pract. 2018;24(1):10611. http://dx.doi.org/10.1080/13814788.2017.1422177

18. Tófoli LF, Gonçalves DA, Fortes S. Somatização e sintomas sem explicação médica. In: Gusso G, Lopes JMC, orgs. Tratado de Medicina de Família e Comunidade: princípios, formação e prática. Porto Alegre: Artmed; 2012. p. 1897-905.

19. Illich I. A expropriação da saúde: nêmesis da medicina. 4a ed. São Paulo: Nova Fronteira; 1975.

20. Moynihan R, Heath I, Henry D. Selling sickness: the pharmaceutical industry and disease mongering. BMJ. 2002;324(7342):886-91. http://dx.doi.org/10.1136/bmj.324.7342.886

21. Castiel LD, Álvarez-Dardet C. A saúde persecutória: os limites da responsabilidade. Rio de Janeiro: Editora Fiocruz; 2007.136 p.

22. Bem Estar [acesso 2018 Abr 6]. Disponível em: http://g1.globo.com/bemestar/

23. Cascudo LC. Coisas que o povo diz. $2^{\mathrm{a}}$ ed. São Paulo: Global Editora; 2009.

24. Speake J, Simpson J. The Oxford Dictionary of Proverbs. 5th ed. Nova York: Oxford University Press; 2008.

25. Gomes JP. É melhor prevenir do que remediar? A ciência dos ditados populares: Centro de pesquisa usa expressões do dia a dia para divulgar estudos envolvendo radicais livres. Jornal da USP [Internet]. [acesso 2018 Mar 31]. Disponível em: http://jornal.usp.br/ universidade/e-melhor-prevenir-do-que-remediar-a-ciencia-dos-ditados-populares/

26. US Preventive Services Task Force, Bibbins-Domingo K, Grossman DC, Curry SJ, Davidson KW, Epling JW Jr, García FA, et al. Statin Use for the Primary Prevention of Cardiovascular Disease in Adults: US Preventive Services Task Force Recommendation Statement. JAMA. 2016;316(19):1997-2007. http://dx.doi.org/10.1001/jama.2016.15450

27. Chou R, Dana T, Blazina I, Daeges M, Jeanne TL. Statins for Prevention of Cardiovascular Disease in Adults: Evidence Report and Systematic Review for the US Preventive Services Task Force. JAMA. 2016;316(19):2008-24. http://dx.doi.org/10.1001/jama.2015.15629

28. Neves CMFP, Deveza M, Teixeira RJ. Hipotireoidismo subclínico em idosos na atenção primária: ênfase na prevenção quaternária. Rev Hosp Univ Pedro Ernesto. 2016;15(3):227-34. http://dx.doi.org/10.12957/rhupe.2016.29448

29. LeFevre ML; U.S. Preventive Services Task Force. Screening for thyroid dysfunction: U.S. Preventive Services Task Force recommendation statement. Ann Intern Med. 2015;162(9):641-50. http://dx.doi.org/10.7326/M15-0483

30. Villar HC, Saconato H, Valente O, Atallah AN. Thyroid hormone replacement for subclinical hypothyroidism. Cochrane Database Syst Rev. 2007;(3):CD003419. http://dx.doi.org/10.1002/14651858.CD003419.pub2

31. Almeida Filho ND, Rouquayrol MZ. Introdução à Epidemiologia. 4ª ed. Rio de Janeiro: Guanabara Koogan; 2013.

32. Ilic D, Neuberger MM, Djulbegovic M, Dahm P. Screening for prostate cancer. Cochrane Database Syst Rev. 2013;(1):CD004720. http:// dx.doi.org/10.1002/14651858.CD004720.pub3

33. Modesto AAD, Lima RLB, D’Angelis AC, Augusto DK. Um novembro não tão azul: debatendo rastreamento de câncer de próstata e saúde do homem. Interface (Botucatu). 2018;22(64):251-62. http://dx.doi.org/10.1590/1807-57622016.0288

34. Ammer C. The American Heritage dictionary of idioms. Boston: Houghton Mifflin; 1997.

35. Starfield B. Is US health really the best in the world? JAMA. 2000;284(4):483-5.

36. Makary MA, Daniel M. Medical error-the third leading cause of death in the US. BMJ. 2016;353:i2139. http://dx.doi.org/10.1136/bmj.i2139

37.Pereira MG, Galvão TF. Heterogeneidade e viés de publicação em revisões sistemáticas. Epidemiol Serv Saúde. 2014;23(4):775-8. http:// dx.doi.org/10.5123/S1679-49742014000400021

38. Kicinski M, Springate DA, Kontopantelis E. Publication bias in meta-analyses from the Cochrane Database of Systematic Reviews. Stat Med. 2015;34(20):2781-93. http://dx.doi.org/10.1002/sim.6525 
39. Ross JS, Tse T, Zarin DA, Xu H, Zhou L, Krumholz HM. Publication of NIH funded trials registered in ClinicalTrials.gov: cross sectional analysis. BMJ. 2012;344:d7292. http://dx.doi.org/10.1136/bmj.d7292

40. Plataforma Brasil [acesso 2018 Jan 23]. Disponível em: //plataformabrasil.saude.gov.br/login.jsf

41. Costa JF. A medicina como projeto social: o controle dos corpos e sexos. In: Souza AN, Pintaguy J, orgs. Saúde, corpo e sociedade. Rio de Janeiro: Editora UFRJ; 2006. p. 133-43.

42. McCaffery KJ, Jansen J, Scherer LD, Thornton H, Hersch J, Carter SM, et al. Walking the tightrope: communicating overdiagnosis in modern healthcare. BMJ.2016;352:i348. http://dx.doi.org/10.1136/bmj.i348

43. Ruiz-Cantero MT, Cambronero-Saiz B. La metamorfosis de la salud: invención de enfermedades y estrategias de comunicación. Gac Sanit. 2011;25(3):179-81. http://dx.doi.org/10.1016/j.gaceta.2011.03.004

44. Gérvas J, Gavilán E, Gorricho J. Medicalización del envejecimiento y síndrome por déficit de testosterona. Bol Inform Farmacot Nav. 2012;20(4):1-8.

45. Tesser CD. Prevenção Quaternária para a humanização da Atenção Primária à Saúde. Mundo Saúde. 2012;36(3):416-26.

46. Fabbri A, Gregoraci G, Tedesco D, Ferretti F, Gilardi F, lemmi D, et al. Conflict of interest between professional medical societies and industry: a cross-sectional study of Italian medical societies' websites. BMJ Open. 2016;6(6):e011124. http://dx.doi.org/10.1136/ bmjopen-2016-011124

47. Cochrane. [acesso 2018 Jun 23]. Available from: www.cochrane.org/ http://www.cochrane.org/pt/evidence

48. U.S. Preventive Services Task Force. [acesso 2018 Jun 23]. Disponível em: https://www.uspreventiveservicestaskforce.org

49. Quick summaries of evidence-based medicine. [acesso 2018 Jun 23]. Disponível em: http://www.thennt.com

50. Portal SBE. Saúde Baseada em Evidências. [acesso 2018 Jun 23]. Disponível em: http://psbe.ufrn.br

51. Laskin DM. The art of doing nothing. J Oral Maxillofac Surg. 1985;43(2):72. http://dx.doi.org/10.3109/13814788.2012.733691

52. Demicheli V, Jefferson T, Ferroni E, Rivetti A, Di Pietrantonj C. Vaccines for preventing influenza in healthy adults. Cochrane Database Syst Rev. 2018;2:CD001269. http://dx.doi.org/10.1002/14651858.CD001269.pub6

53. Fenner F, Henderson DA, Arita I, Jezek Z, Ladnyi ID. Smallpox and its eradication. Genebra:World Health Organization; 1988 . [cited 2018 Jun 23]. Available from: http://www.who.int/iris/handle/10665/39485

54. Brasil. Instituto Nacional de Câncer José Alencar Gomes da Silva (INCA). Coordenação de Prevenção e Vigilância. Divisão de Detecção Precoce e Apoio à Organização de Rede. Diretrizes Brasileiras para o Rastreamento do Câncer do Colo do Útero. 2ª ed. Rio de Janeiro: INCA;2016. [cited 2018 Jun 10]. Available from: http://www1.inca.gov.br/inca/Arquivos/DDiretrizes_para_o_Rastreamento_do_cancer_ do_colo_do_utero_2016_corrigido.pdf

55. Brasil. Ministério da Saúde. Secretaria de Atenção à Saúde. Departamento de Atenção Básica. Rastreamento. Brasília: Ministério da Saúde; 2010.

56. Rolfe A, Burton C. Reassurance after diagnostic testing with a low pretest probability of serious disease: systematic review and meta-analysis. JAMA Intern Med. 2013;173(6):407-16. http://dx.doi.org/10.1001/jamainternmed.2013.2762

57. Norman AH, Tesser CD. Prevenção quaternária na atenção primária à saúde: uma necessidade do Sistema Único de Saúde. Cad Saúde Pública. 2009;25(9):2012-20. http://dx.doi.org/10.1590/S0102-311X2009000900015 